\title{
Architecture, Science and Exhibit: Yesterday and Today
}

\author{
Simona Canepa and Marco Vaudetti \\ DAD Department of Architecture and Design, Politecnico di Torino, Torino 10125, Italy
}

\begin{abstract}
Architecture and science have always been interrelated for educational purposes. For this reason the course of Interior Architecture and Exhibit Design at Master of Science in Architecture Construction City of Politecnico di Torino, starting from the knowledge of the role of the Academy and its scientific content, proposed new and current forms of exhibits and communication in respect of the courtly architecture that is called to emphasize with its language the authority and perennial values of the sciences.
\end{abstract}

Key words: Historical buildings, exhibition, flexibility.

\section{Introduction}

Architecture and science have always been interrelated for educational purposes: it is no coincidence that prestigious institutions such as the Istituto Veneto di Scienze, Lettere ed Arti in Venice, the Accademia Nazionale dei Lincei in Rome, the Società Nazionale di Scienze, Lettere ed Arti in Naples, the Royal Institute in London, the Smithsonian Institute in Washington D.C., to name but a few, have their head office in stately structures that over time have become a symbol in the dissemination of knowledge. The Academy of Sciences of Turin does not escape this assumption: its most prestigious halls - the Sala dei Mappamondi and the historical archive-have always been in dialogue with the public and host the most important institutional events.

\section{The Academy of Sciences of Turin and Its} Mission

The Academy of Sciences of Turin, established in 1783 at the behest of King Vittorio Amedeo III, was born as a place of research and study in science and then expanded its skills in the literary field. In 2000 it became a legal entity under private law with the

Corresponding authors: Simona Canepa, assistant professor; Marco Vaudetti, full professor; research fields: interiors and exhibit. E-mail: simona.canepa@polito.it, marco.vaudetti@polito.it. drafting of a Statute and today plays a role of great importance in the cultural field with the aim of spreading knowledge.

It is divided into two classes, respectively of Physical, Mathematical and Natural Sciences, and of Moral ones, Historical and Philological Sciences. Periodically, conferences are held in which members present the results of their research to the community and activities are also organized for a wider audience, such as conferences, educational activities, seminars.

The didactic activity that the Institution is carrying out with the schools of the city has a very important role. In-depth workshops are organized with primary and secondary school classes about people who have written the history of the Academy, such as the mathematician Luigi Lagrange or the chemist Amedeo Avogadro. The children are put to the test directly with small experiments, so as to give substance to the scientific narratives and give them the feeling of being small scientists. The Academy has also set up alternating school-work courses that allow students to get closer to the usual activities which take place within the library and archive, communication and enhancement of the heritage [1].

\section{The History}

Earl Angelo Saluzzo di Monesiglio (1734-1810), the doctor Giovanni Francesco Cigna (1734-1790) and the mathematician Luigi Lagrange (1736-1813), in 1757 
gave life to the Turin Private Society; they were moved by the need to have spaces where they could do research, since the schools lacked them. This cultural model was supported by Prince Vittorio Amedeo III.

In 1760 an attempt was made to transform the Private Society into the Royal Academy on the model of the Académie des Sciences, but it was held back by Carlo Emanuele II. Nevertheless, the institution's activity continued, becoming a full member of the European scientific circuit.

With the ascent to the throne of Vittorio Amedeo III, in 1774 , the private company was able to propose itself in its own right as a centre for scientific, economic and cultural research throughout the territory of Piedmont, with the aim of actively collaborating in the economic and administrative management of the activities of the State, as was already the case in the capital cities of Paris, London, Berlin, Stockholm and Petersburg.

On October 30, 1783, Vittorio Amedeo III proclaimed the birth of the Royal Academy of Sciences of Turin. The king undertook to provide an annual budget for the financial support of the institution, and an appropriate location, the building of the College of Nobles in the city center. The motto "Veritas et utilitas" was chosen to express the Academy's commitment to scientific progress and in favour of the State.

In 1800, following the French occupation, the Academy was refounded as the National Academy of Sciences, Letters and Arts. In 1801 Napoleon established the Class of Littérature et Beaux arts, which in 1815, with the return of the Savoy family to Turin, became the Class of Moral, Historical and Philological Sciences. With the advent of Fascism, the Academy will live through difficult years. After the Second World War a period of great recovery and flourishing of the Academy began thanks to the restoration of the headquarters and the enhancement of the huge library heritage [2].

\section{The Head Office}

The Academy of Sciences is housed in a seventeenth-century building designed for the Jesuit order and built between 1679 and 1687 at the behest of Maria Giovanna Battista of Savoy Nemours. It was a college that was to house the offspring of the noble families of the time and inside housed a refectory, the canteen, the dormitories, a theater, and a chapel. The architect Guarino Guarini was given the paternity of the palace. The building site was directed by Michelangelo Garove, his pupil. In 1784 King Vittorio Amedeo III granted a wing of the palace to the newly established Academy of Sciences (Fig. 1).

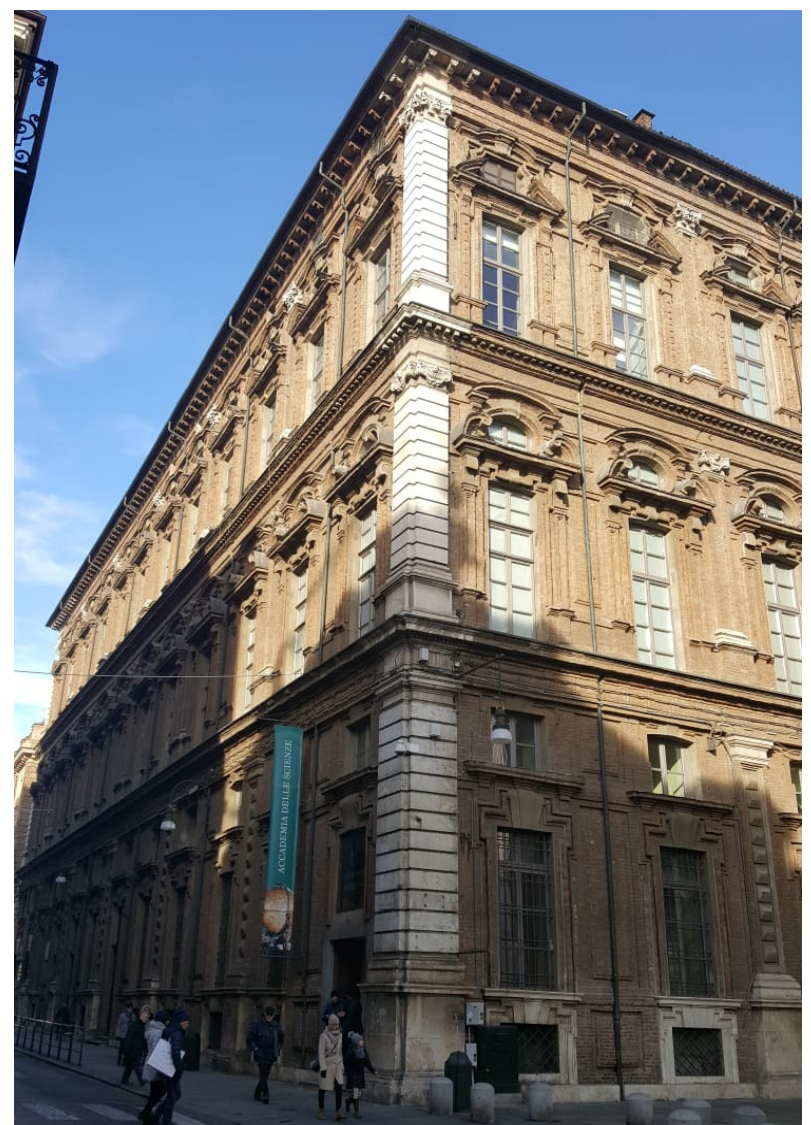

Fig. 1 View of the exterior of the building in the city centre of Turin.

The facades of the palace are characterized by three floors of overlapping orders, of equal height, distinguished by bands of triglyphs, enriched by the decorations of the sumptuous frames of the openings: on the first floor the tympanums are based on classical designs, on the second floor are made up of a fastigium with curved handles, on the third floor resume a 
geometric scan. The entrance portal was created by Antonio Maria Talucchi in 1824 on the occasion of the opening of the Egyptian Museum.

Over the centuries the palace has hosted various activities, such as the Museum of Natural Sciences, an astronomical observatory destroyed by bombing during World War II, the Museum of Antiquities and the Savoy Gallery. Today it houses the Egyptian Museum. The main floor of the wing occupied by the Academy of Sciences, which is accessed from the monumental atrium and a staircase designed by Guarino Guarini houses the Hall of Globes (Fig. 2), once home to the theatre of the College. This room owes its name to the presence of two globe maps of 110 $\mathrm{cm}$ in diameter made by the Venetian cartographer Vincenzo Maria Coronelli [3].

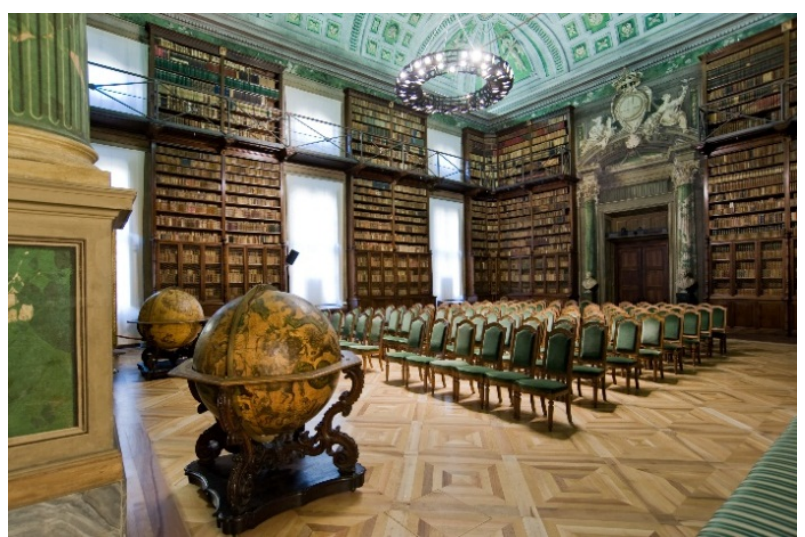

Fig. 2 The Hall of Globes.

In the precious decorated vault, the representations of the Academy's sciences stand out at the four corners: mechanics and mathematics illustrated with a pinion, a cogwheel, a compass and geometric figures; geography and astronomy, represented with a compass, an astrolabe, and a map; physics and chemistry, with a thermometer and a retort; and finally the natural sciences with a fossil and a crocodile. The room was initially used for the meetings and in 1886 it took on its present appearance characterized by the decorated vault and the bookshelves arranged on the sides.

From the Hall of Globes one enters the Reading Room through two doors surmounted by portraits of Pythagoras and Euclid. It also has the walls used as a library where the oldest collections are kept. The ceiling is frescoed with subjects representing ornithology. Following this, we come to the Catalogues Room (Fig. 3).

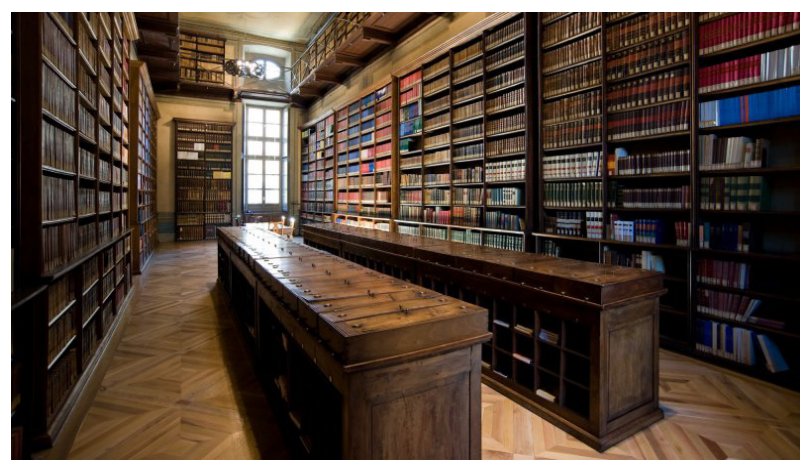

Fig. 3 The Catalogue Room.

On the upper floor are the Vallauri Room, used for conferences and educational activities, and the Chà Room [4].

In 2005, the headquarters underwent restoration work financed by the Compagnia San Paolo (Fig. 4).

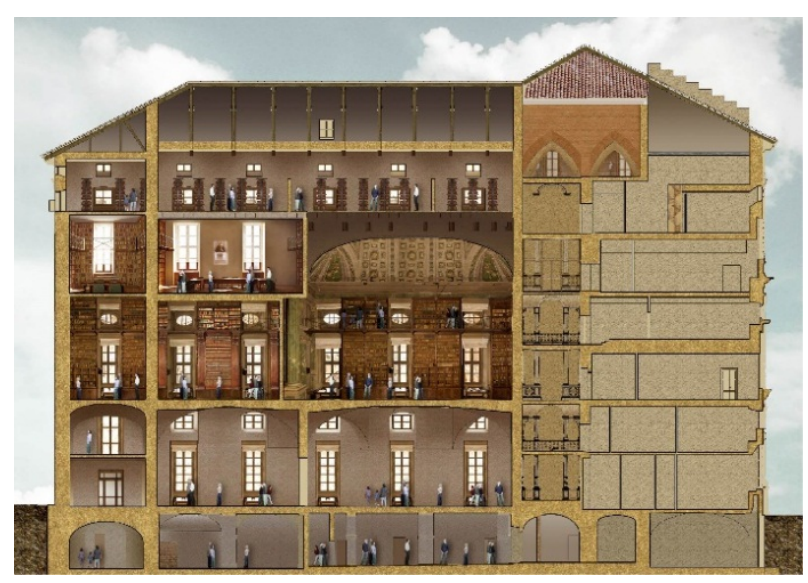

Fig. 4 Section of the building.

The renovation, re-functionalisation, consolidation and adaptation to fire regulations have made all the spaces historically used by the Academy usable and functional, allowing the creation of new rooms for the storage of volumes, in line with modern conservation standards. Starting from the basement, large rooms have been opened with the function of storage for about four kilometers of shelving, where there are collections of periodicals of the Academy. On the ground floor two large rooms have been restored, which at the time of 
the Jesuit College housed the chapel. Offices have also been set up for the administrative activities of the Institution [5].

At the same time of the building restoration, the computerized cataloguing and partial digitization of the book heritage were carried out.

\section{The Teaching Experience of the Politecnico di Torino in the Academy Rooms on the Ground Floor}

During the restoration of the ground floor rooms, an unprecedent collaboration was developed between the Academy of Sciences and the Course in Interior Architecture and Exhibition Design held by professors Marco Vaudetti and Simona Canepa at the Master of Science in Architecture Construction City of the Politecnico di Torino. The course aims to deepen the design experience in the field of interiors with specific reference to the renovation of existing spaces for exhibition purposes and provides real effects aimed at the application of the methods and criteria illustrated during the lessons.

The recovery of the ground floor spaces as an exhibition hall, therefore, immediately appeared to be a stimulating opportunity for the students who, organized in working groups, have developed various proposals, realizing them in the autumn of 2016, in the middle of the building site activities, and in the year after [5].

Considering that the Academy of Sciences has always aimed at an audience of young people, it immediately seemed consistent to propose design experiments of young students who start from the knowledge of the role of the Academy and its scientific content to propose new and current forms of exhibits and communication in respect of the courtly architecture that is called to emphasize with its language the authority and perennial values of the sciences.

The projects developed are highly respectful of the historical and architectural characteristics of the building container recovered to new functions and aim to establish a dialogue with it, proposing setting solutions that tend to highlight the choice of materials and finishes that the Academy of Sciences has operated during the delicate phase of restoration.

From the exhibition point of view, the projects propose both a permanent solution, aimed at illustrating the centuries-old history and activities of the Academy of Sciences in enhancing and disseminating historical-scientific knowledge, and a space for temporary exhibitions in which, in rotation, significant materials made available by the Academy of Sciences can be placed, including rare texts, incunabula, illuminated manuscripts, music texts, scientific texts, archival documents, colour and statuary plates.

These projects have inaugurated the exhibition spaces as part of the international event The International Federation of Interior Architects/Designers, which organizes for Saturday, May 27, 2017 the World Interiors Day, the day celebrated around the world, which involves professionals, national associations, design enthusiasts and the general public to explore the creativity, imagination, vision and passion in relation to the role of the Interior in society and culture. The event entitled Imaging one space: science and history meet design testifies to the close link between the Academy of Sciences and the younger generations, an objective that has always been shared by the Institution [6].

The rooms on the ground floor of the building, home to the ancient chapel of the former Jesuit College, restored to host temporary exhibitions, are characterized by two large elliptical-shaped chandeliers with metal structure, which combine well with the geometry of the vaults and the decorative motifs of the rooms, in particular the decorations of the door above the restored interior doors and windows (Fig. 5). 


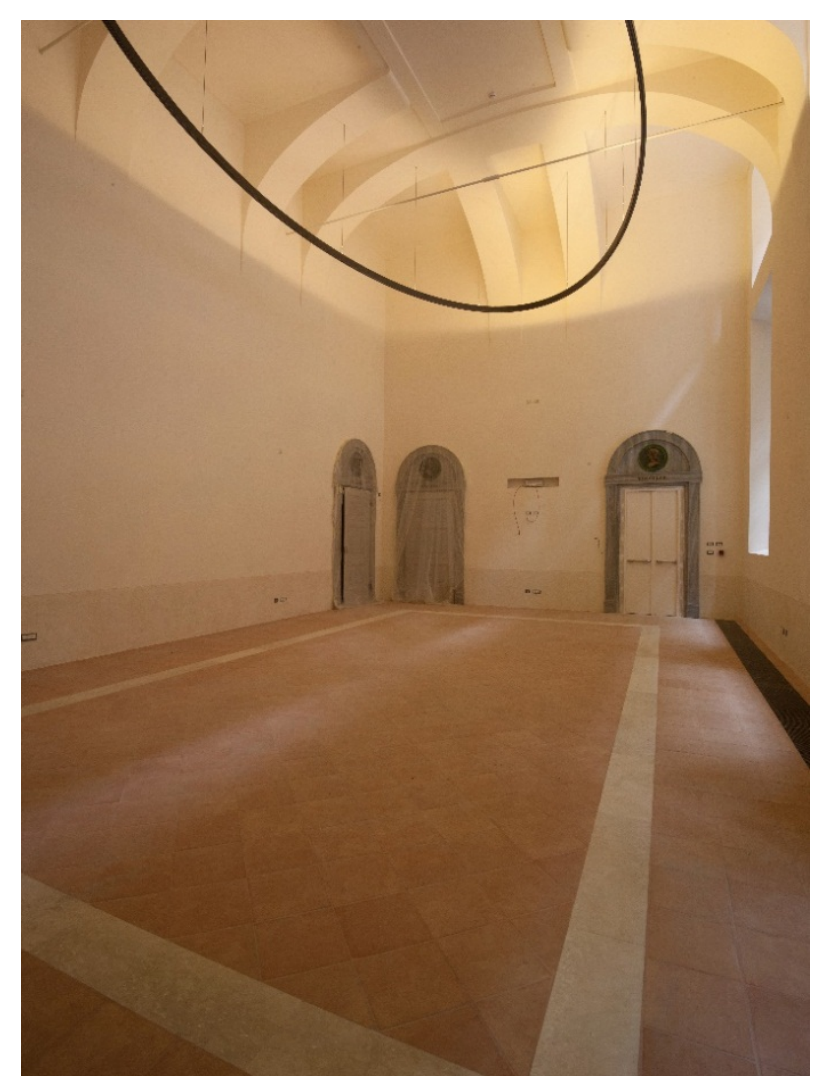

Fig. 5 View of the room on the ground floor (photo courtesy by Daniele Fazzari).

\subsection{Main Features of the Exhibits Proposed in the} Rooms on the Ground Floor

All the proposals are characterized by a search for flexibility in line with the concept of temporary exhibition in relation to different types of visiting public.

The exhibition systems designed take into account aspects related to:

- formal and dimensional coherence in relation to the architectural context

- use, as far as possible, of the lighting system provided by the two chandeliers in the centre of the ceiling of the rooms

- easy mounting, with dry system

- easy disassembly

- good compatibility with interactive and multimedia solutions

It is also intended to highlight the philosophy of storytelling and the often innovative solutions to communicate to the public the mission of the Academy with solutions that are easily understood by different types of audiences. In this regard, the target audience of visitors is as follows:

- an average user driven to the visit by simple curiosity and to whom we propose an exhibition solution attentive to the simple disclosure;

- a user consisting of schoolchildren, with a guided tour and to whom we propose a treatment of the themes of the visit with frequent interactive moments;

- an expert user for whom are proposed finds and topics of specialist significance [7].

\subsection{The Main Exhibition Solutions for Presenting Science Concepts}

\subsubsection{How to Use the Space}

The space can be organized starting from a modular grid, divided into flexible modules which give life to three-dimensional exhibition configurations; the displays in aluminum profiles and fittings with multiple ways, allow you to create different combinations and variable exhibition paths depending on the scientific order (Figs. 6-8).

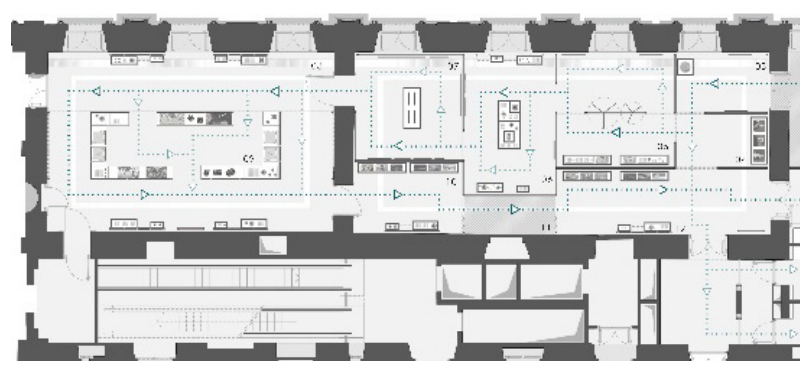

Fig. 6 General plan.

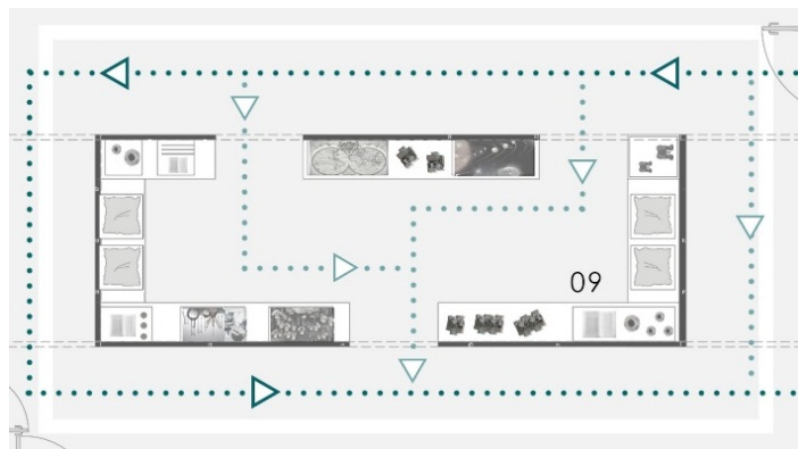

Fig. 7 Detail of one of the room. 


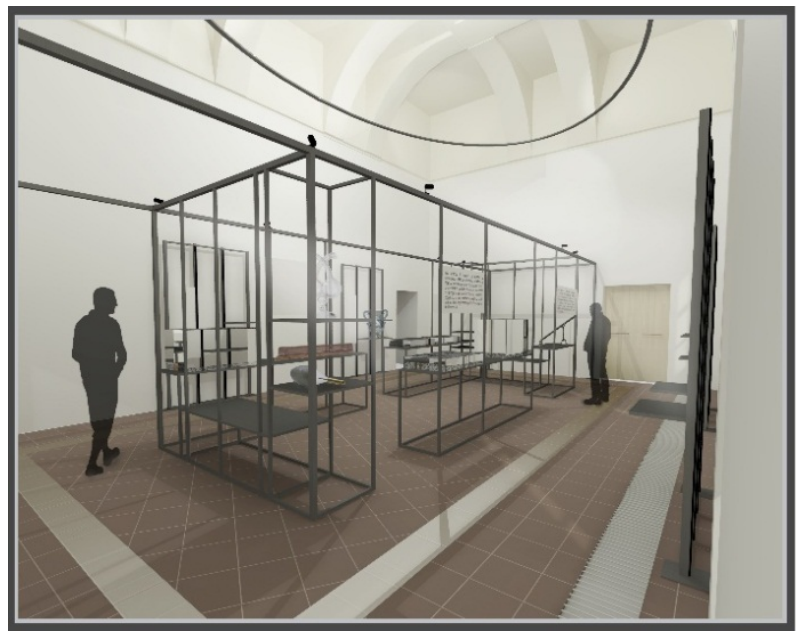

Fig. 8 Flexible modules.

The panels, arranged as if they were open books, recall the rich archival heritage of the Academy and are intended to direct visitors into the room. The panels can be integrated with shop windows, multimedia tables and interactive tables. The displays have the function of allowing visitors to virtually access texts and documents that would not be possible to expose to the public because of their precarious state of preservation (Figs. 9-11).

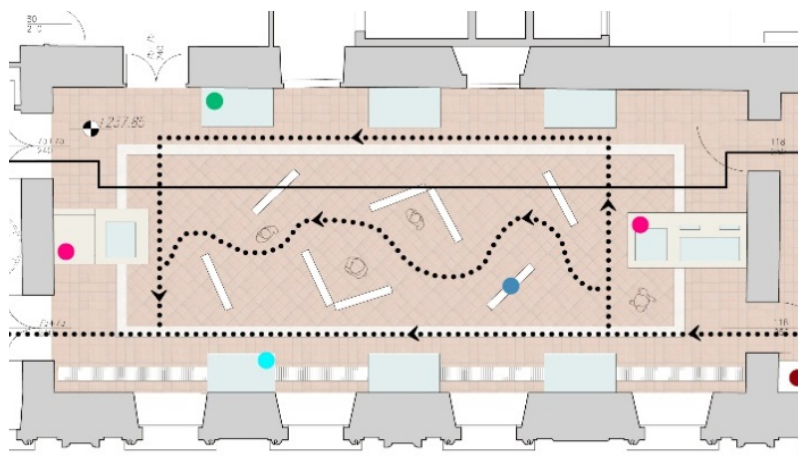

Fig. 9 Panels organization as open books.

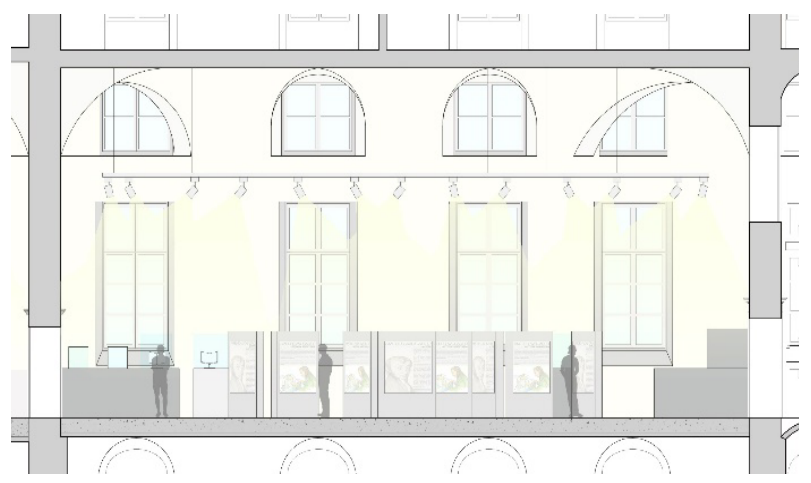

Fig. 10 Longitudinal section.

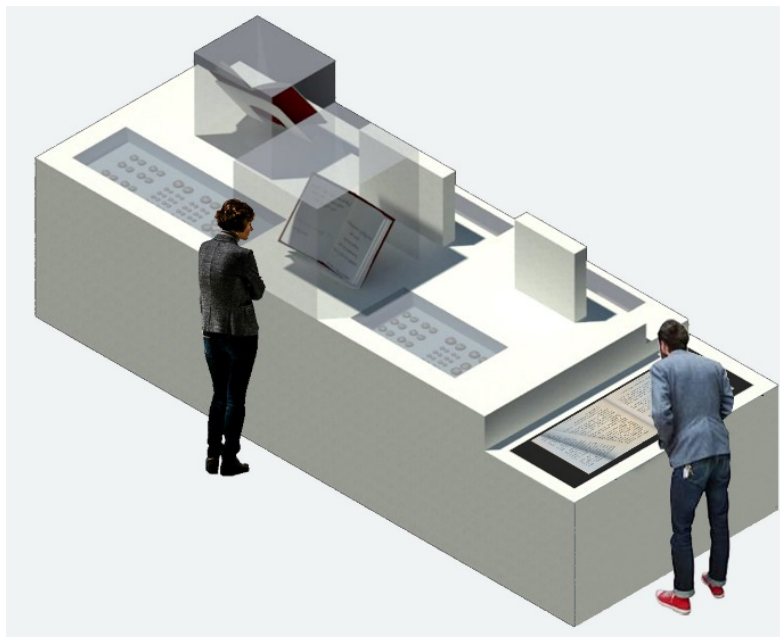

Fig. 11 Interactive table.

The exhibition is developed by a combination of panels along the entire length of the exhibition spaces. The organization of the panels arranged perpendicularly creates simple display niches equipped with two-dimensional hanging elements and displays, or equipped with simple bases or protected by display cases. This set of modules, stable by form, constitutes the main partition element of the exhibition rooms, generating visiting paths; it also constitutes the support for the storytelling of the chronological events of the Academy (Figs. 12 and 13).

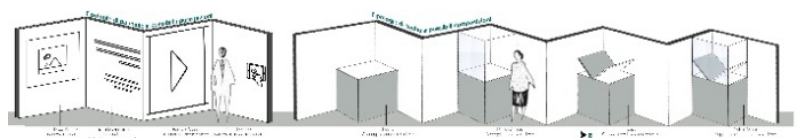

Fig. 12 Combination of panels.

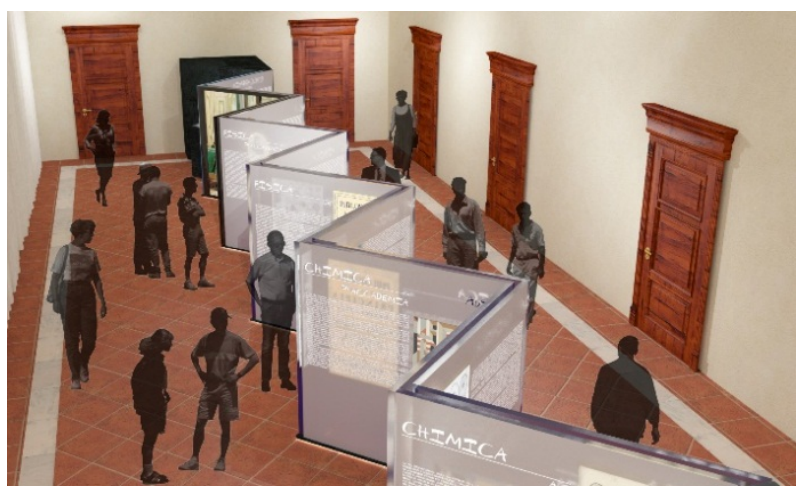

Fig. 13 Spatial organization.

5.2.2 The Suggestions Arising from the New Structure of the Halls

The pendant lighting elements generate the ground 
imprint of the installation system, thus becoming the main theme of the entire installation: in the main room, two table display cases are placed at the ends of the largest diameter of the ellipse, while the longer sides are occupied by vertical metal bars supporting two-dimensional elements. In the other room, vertical hanging elements with bases and glass display cases are alternated (Figs. 14 and 15).

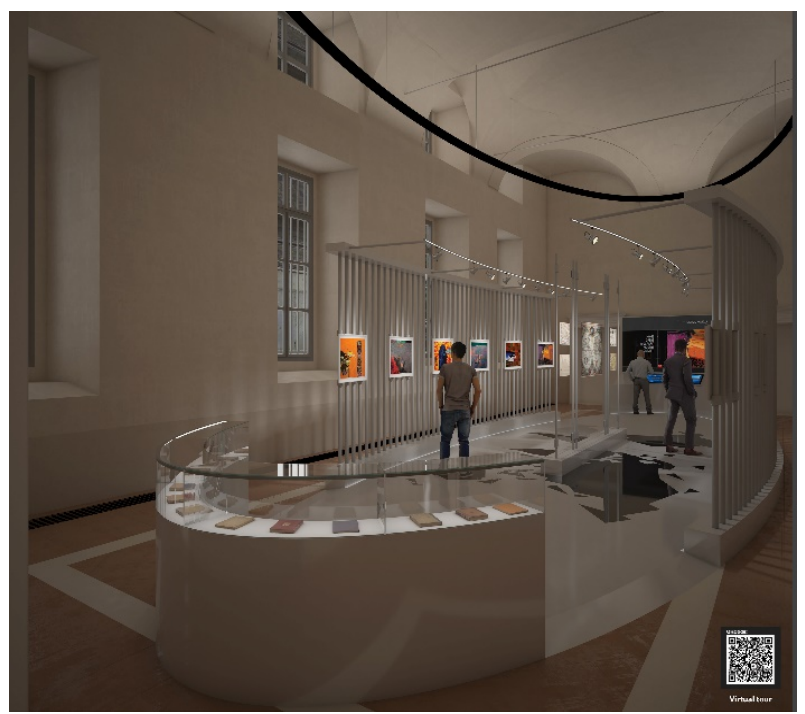

Fig. 14 View of the permanent exhibition.

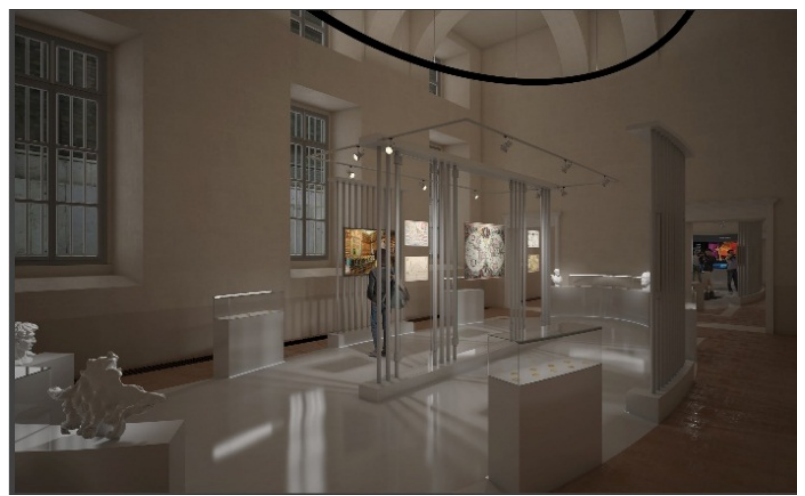

Fig. 15 View of the temporary exhibition.

The theme of the journey is inspired by the elliptical shape of the chandeliers thanks to a structure that resembles the sides of a ship; the exhibition structure is made of circular pillars and steel strands stretched for the display of two-dimensional elements, and houses an interactive table in the center. In the adjoining room, the footprint of the chandelier is organized with support cables for the display of coins and medals and display cases for statuary (Figs. 16 and 17).

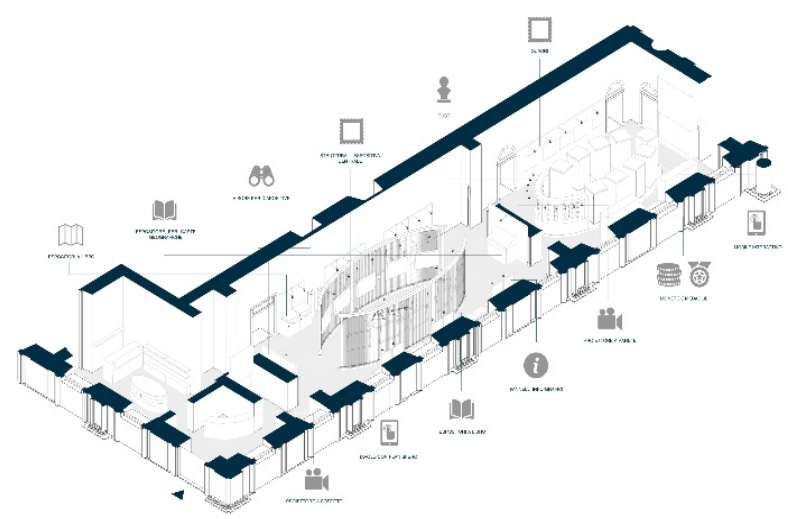

Fig. 16 Axonometric view of the room.

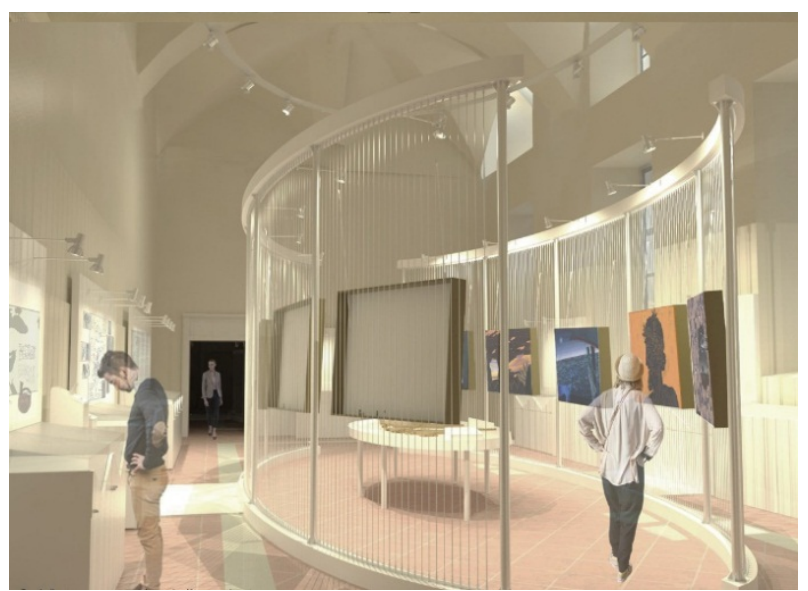

Fig. 17 View of the temporary exhibition.

\subsubsection{The Immersive Space}

A central telescope structure, made up of mdf portals with mobile side panels, becomes an exciting and unexpected space that incorporates the user and guides him along a path that gradually reveals itself (Fig. 18).

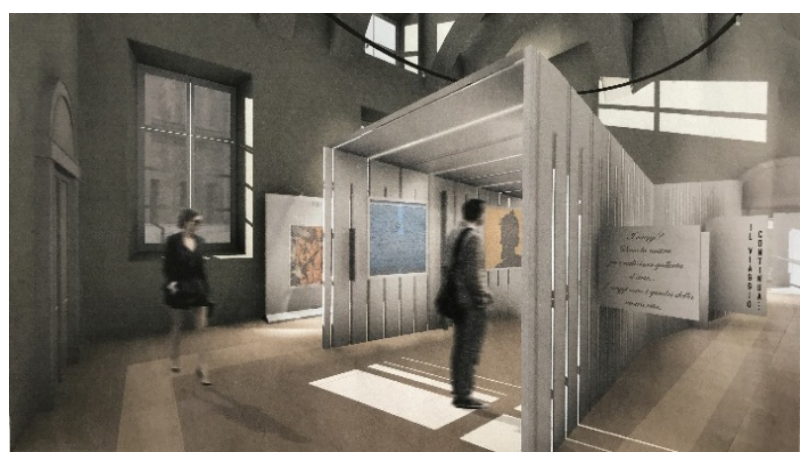

Fig. 18 View of the entrance of tunnel space. 
The sloping walls converging towards a central space recall the keel of a ship that sailed the seas during the journeys of the explorers: the visitor comes to find himself inside a set of exhibition sheets, supported by steel cables which seem to arise from the floor and expand towards the vault of the room (Fig. 19).

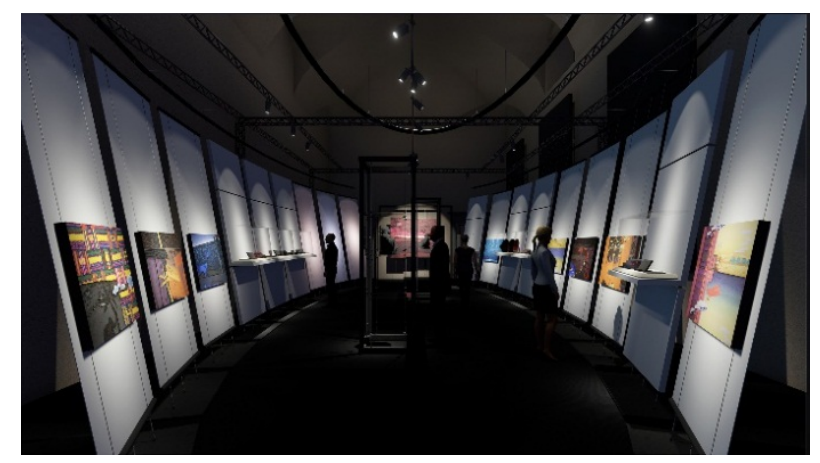

Fig. 19 The panels setting as a keel of a ship.

5.2.4 Elements of the Past Designed in a Current Key

The open shelf organization of a library relives in the exhibition organized in islands made up of panel walls placed perpendicularly to the walls of the main hall. These shelves are organized with showcases, display shelves, drawers, monitors and hanging systems to accommodate exhibition panels. The shelves are connected to each other by a thin platform in order to create exhibition islands dedicated to particular themes. The tables in the next room reproduce the theme of a library reading room: they are organized with display cases for the display of books and are equipped with tablets for consultation of digitized texts (Figs. 20-22).

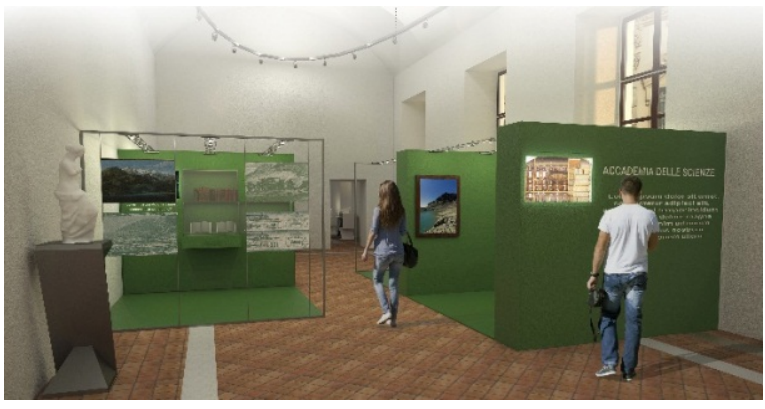

Fig. 20 Exhibit sectors with panels, shelves and showcases.

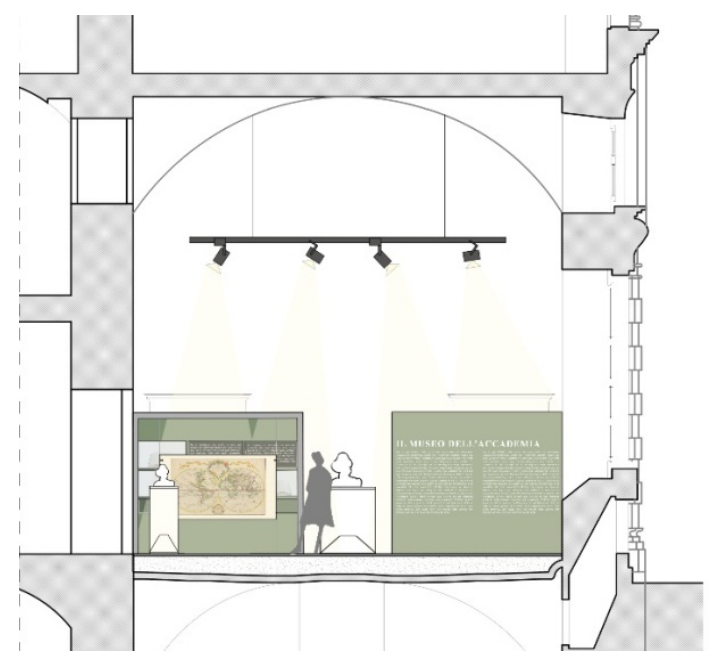

Fig. 21 Cross section of the permanent exhibition space.

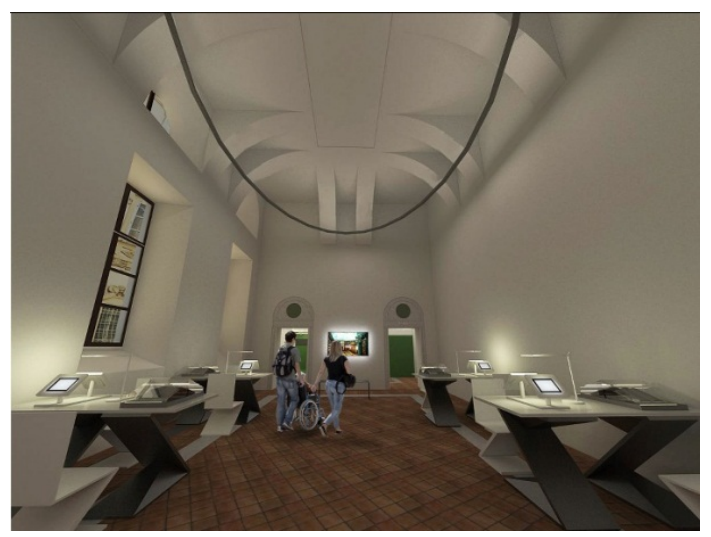

Fig. 22 Tables in the temporary exhibition space. 


\subsubsection{Experimentation with Innovative Solutions}

If on the main floor the globes stand out, on the ground floor the interactive balloon becomes the centre of the exhibition space with spot lighting with an effect in the half-light environment. The display, designed for a multimedia presentation of the main contents of the Academy, is a sphere for dynamic digital display systems, on a ground support containing projector, mirror and lenses and led rings for lighting (Figs. 23 and 24).

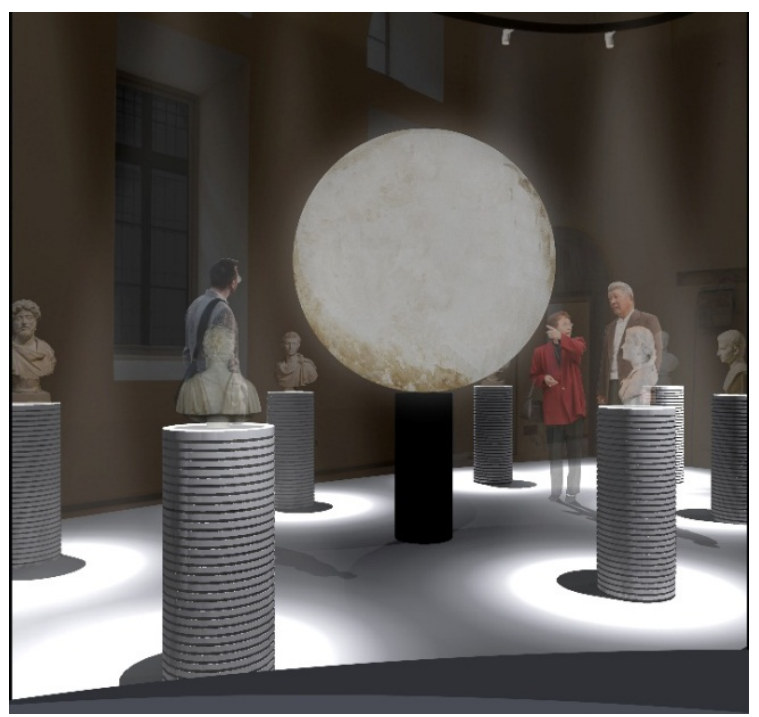

Fig. 23 The interactive balloon in the middle of the space.

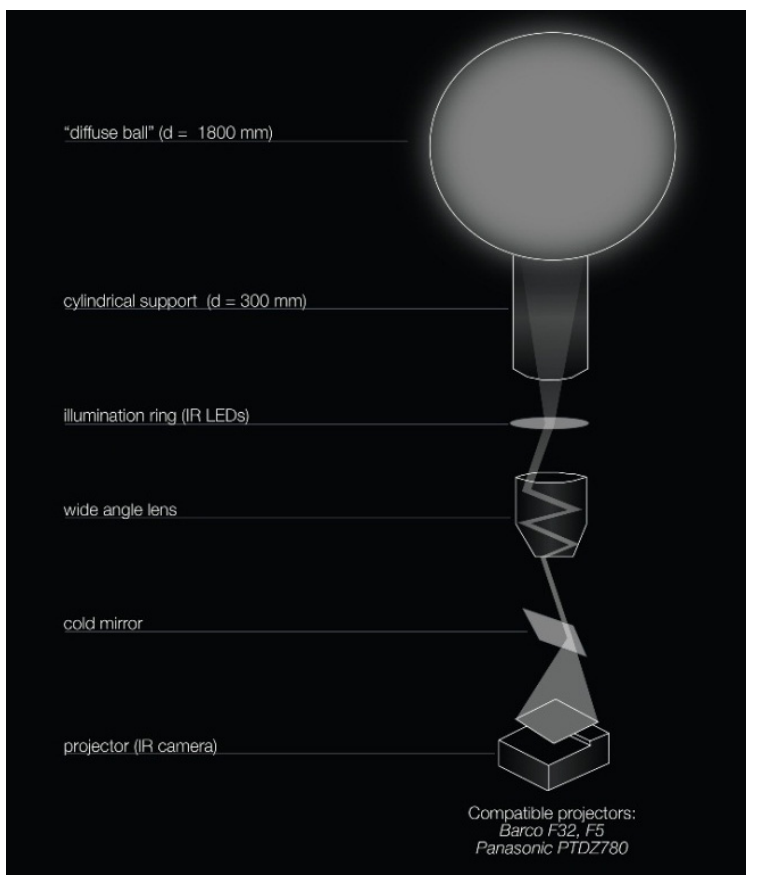

Fig. 24 Interactive balloon Puffersphere M-1800.
The terrestrial globe that characterizes the Hall of Globes is here re-proposed on the ground floor with a sequence of luminous spheres suspended over a long base that through the use of electrical energy creates a $3 \mathrm{D}$ magnetic field. The effect is to have the globes suspended, able to be taken from visitors, observed and repositioned in total freedom (Figs. 25 and 26).

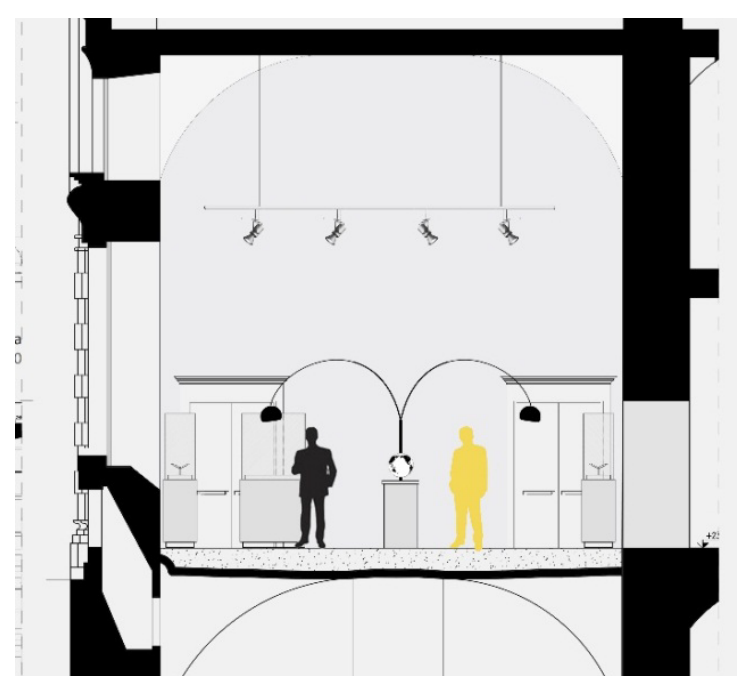

Fig. 25 Cross section.

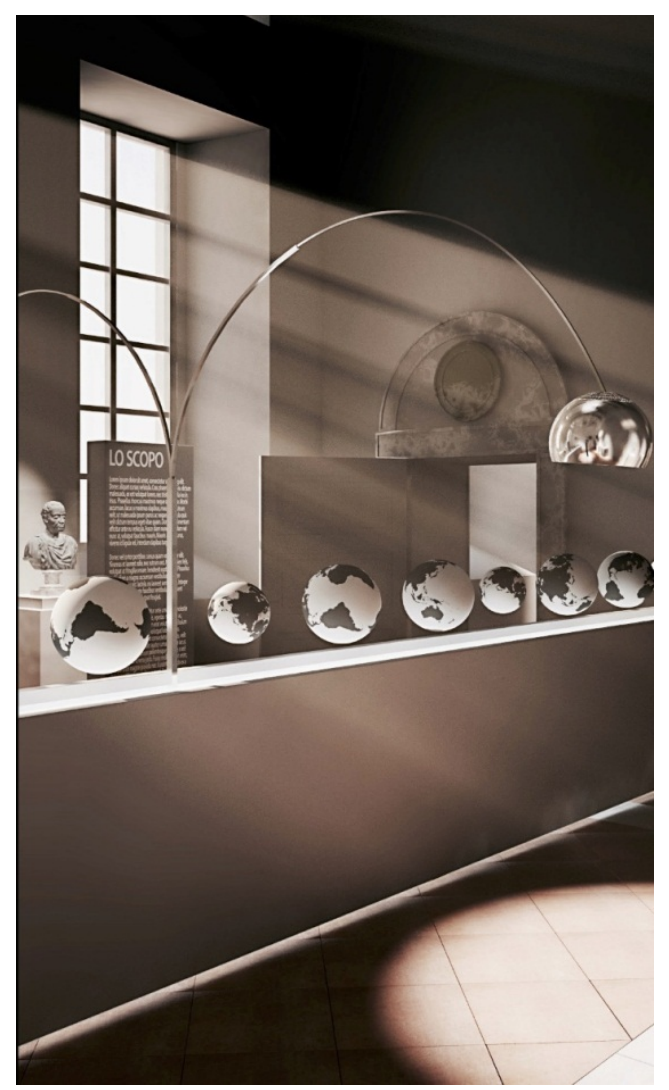

Fig. 26 The suspended globes. 
The holographic display with its mascot positioned on the display case containing the objects guarantees an interactive three-dimensional presentation to visitors of all ages, thanks to effective multimedia comments (Fig. 27).

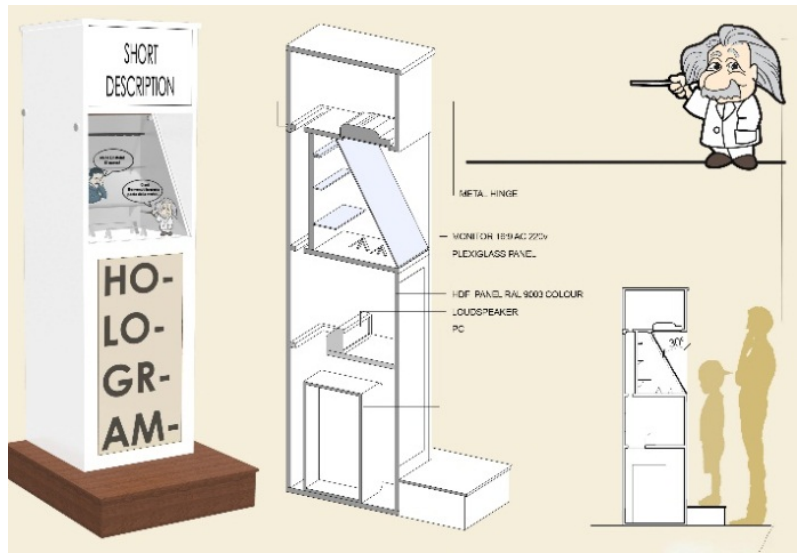

Fig. 27 Details of holographic display.

A continuous element in white mdf ribbon runs along the entire length of the exhibition spaces like a white sheet of paper on which the history of the Academy is written: the ribbon changes shape as the story proceeds, defining the different exhibition sections in which the story unfolds through the insertion of pedestals for busts, touch screens, display cases and panels (Fig. 28).

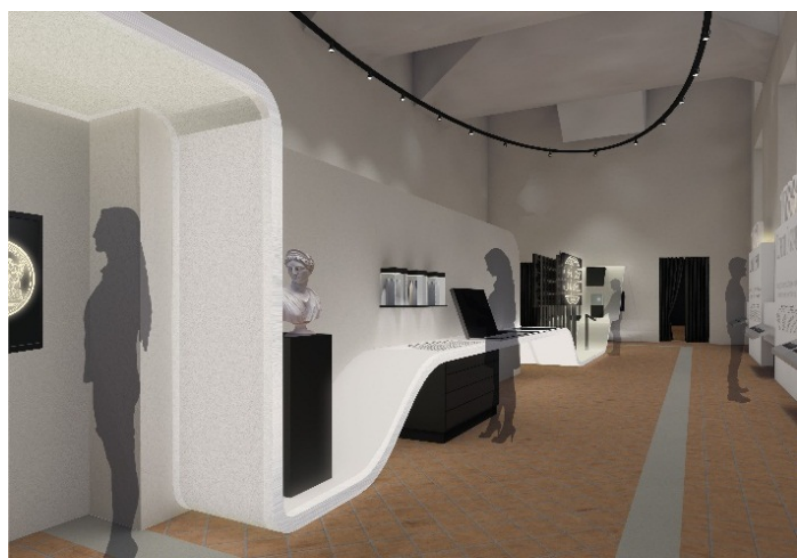

Fig. 28 The ribbon as a functional and exhibition element.

6. The Teaching Experience of the Politecnico di Torino in the Academy Rooms on the Main Floor

The thesis project developed during the Master of
Science in Architecture Construction City [8] takes into strong consideration the requirements of the Academy of Sciences: visible furnishings which are used to exhibit and objects which blend into the space when they have no exhibition function, furnishings which are not fixed, but must be able to give rise to different configurations within the spaces according to needs. Flexibility, versatility, modularity are therefore the characteristics that distinguish the project resulting from the heterogeneity of the preserved documents that is proposed to exhibit. Two types of display units are proposed: Expo up and Lego structure.

Expo up is a parallelepiped in anthracite grey painted aluminium panels with a support frame, which fits well into the rich interior of the Catalogue Room and is both a warehouse and an exhibitor. The interior is equipped with full-height shelving and a wheeled drawer/classifier; the exterior has fixed and mobile display cabinets, which can be positioned at different heights, and removable panels. All accompanied by the presence of a touch monitor (Figs. 29-31).

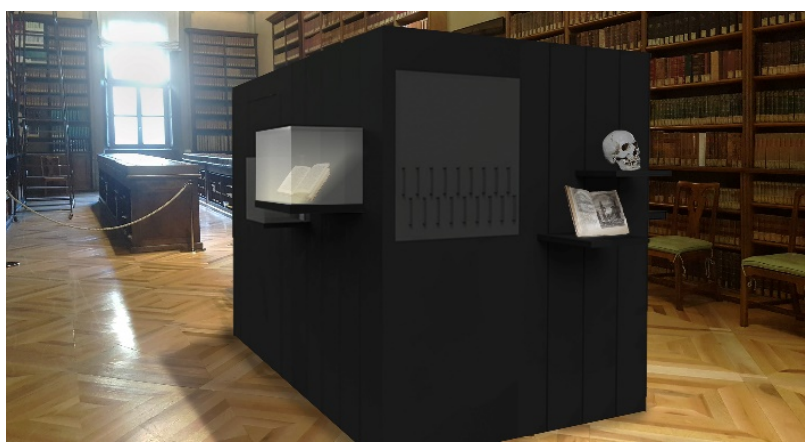

Fig. 29 Expo up modul.

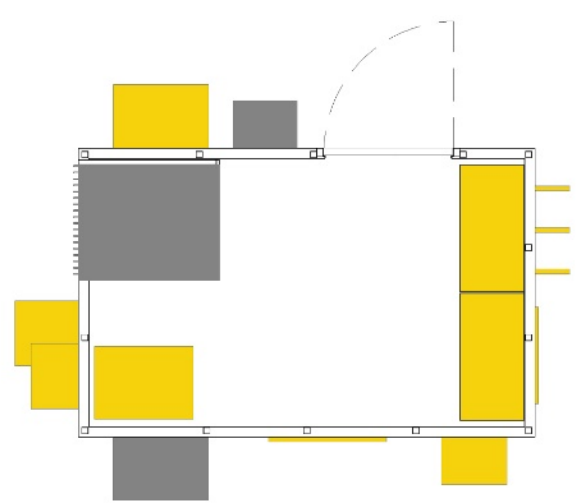

Fig. 30 Expo up modul: in yellow movable furnishing, in gray fixed ones. 


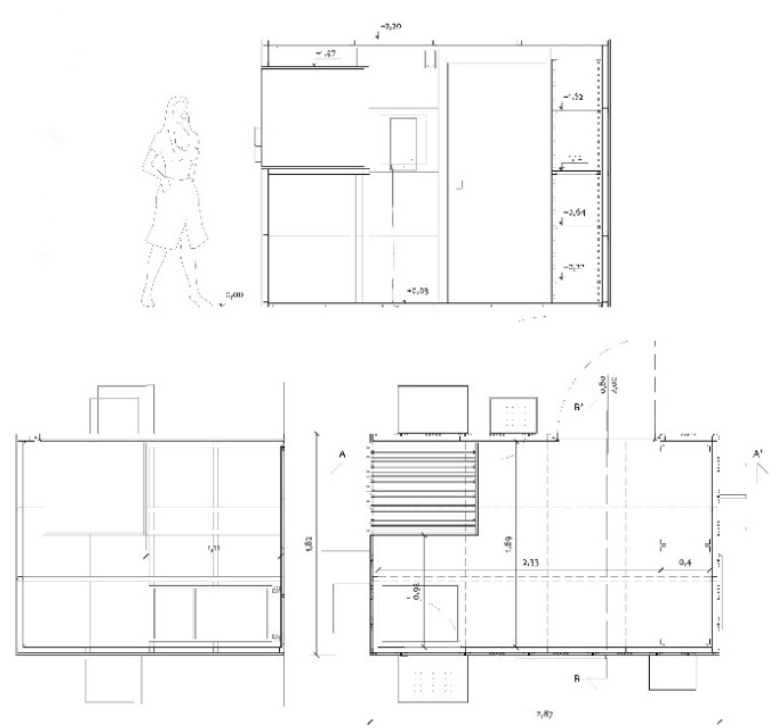

Fig. 31 Expo up modul: plan and sections.

Lego structure is a composition of basic modules each consisting of a closed aluminium box, with a finish similar to that of Expo up, joined together by magnets. The upper part of the module has some variations: a reinforced top can be provided for heavy objects such as busts, a glass top for a simple display case, a top to accommodate tablets, a glass parallelepiped in order to create a double display case (Figs. 32-34).

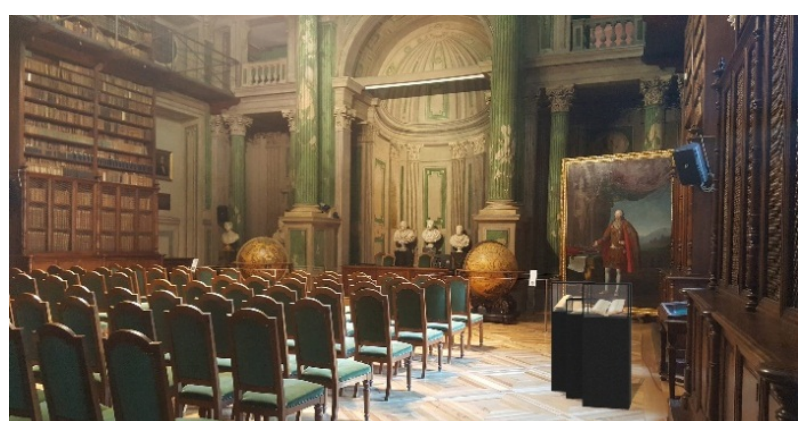

Fig. 32 Lego up in the Hall of Globes.

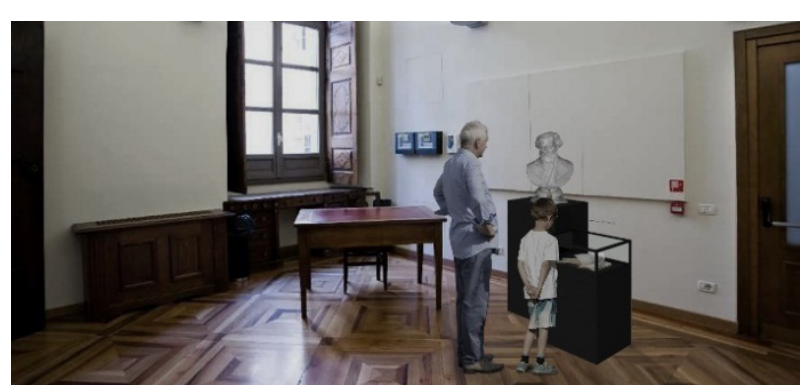

Fig. 33 Lego up in the entrance room.
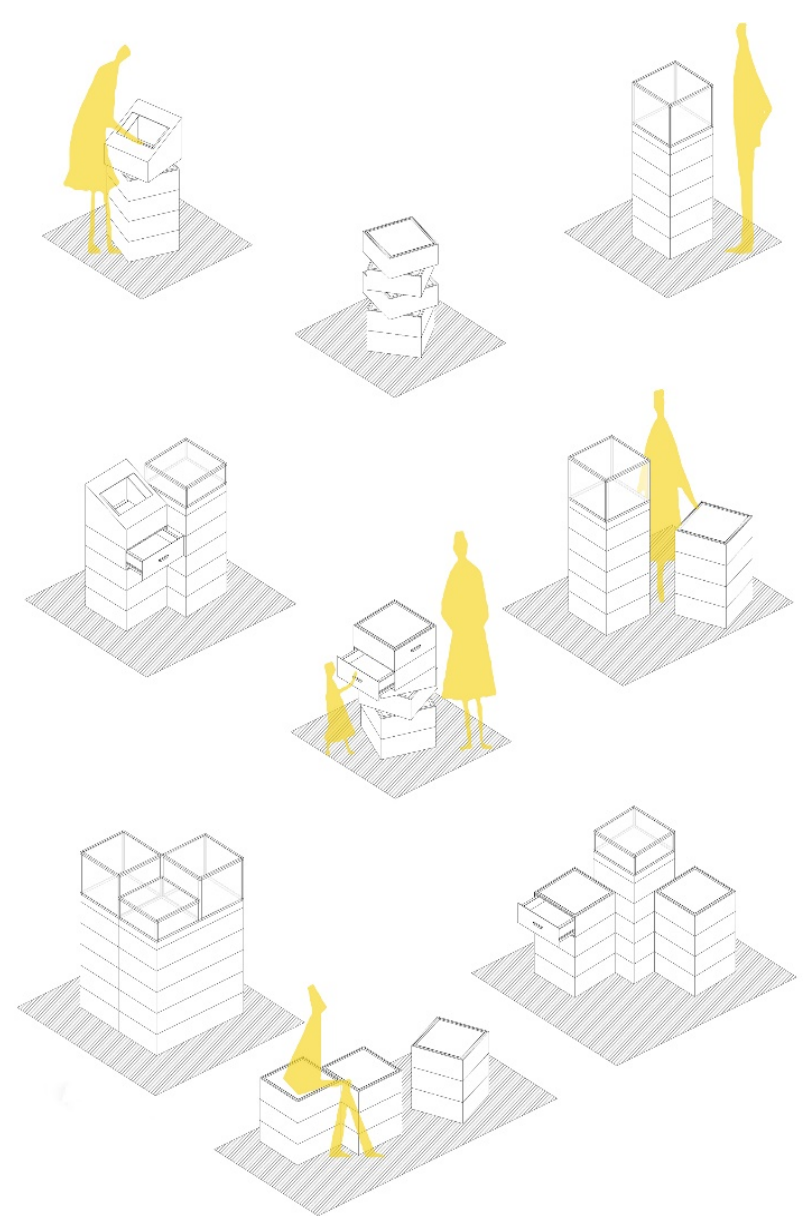

Fig. 34 Lego up different configurations and uses.

\section{Conclusions}

In light of the presentation of the projects by a team of young designers, we think the result obtained is convincing: to explain the different branches of science and the related problems with contemporary exhibition methods, respecting the characteristics of the collections and the architectural context in which the exhibitors are placed.

At the same time, the illustrated proposals highlight a high degree of flexibility in the exhibition that is well suited to the customs of the Academy of Sciences; the Institution intends to present significant elements from its collection to the public on a rotating basis and to organize events and debates with a layout of the spaces that, enhanced by the magnificence of the context, are of interest to an increasingly wide and heterogeneous public. 


\section{References}

[1] Perrone, V. 1988. Tra Società e Scienza, 200 anni di storia dell'Accademia delle Scienze di Torino. Torino: Umberto Allemandi \& C.

[2] Perrone, V. op. cit.

[3] Borgi, E. Mancinelli C. 1869. Short history of Academy of Science., Torino: J.B. Ford and Company.

[4] Borgi, E. Mancinelli C. op.cit.

[5] https://www.icis.it.

[6] https://ifiworld.org/past-wids.

[7] Project works by (in order of presentation)

F. Galluccio-I. Pontiglione-M. Pro

M. Bianco-E. Buratto-G. Giacone-S. Reineri
A. Baffo-L. M. Concordia-C. Uecher
C. Bertinetti-L. Rinaudo-D. Rosa Sentinella
F. Angeleri-C. Bonardi-M. Cirillo
M. Crepaldi-M. Fejr-F. Gagliano
D. Amburatore-E. Busso-E. Casalinuovo
G. Romano-E. Sattanino-E. Schiari
C. Carcione-S. Carraro-F. Tiberti
A. Felli-L. Galleano-M. Madrazo M. Fioretti-D. Salvucci-M. Sentinelli

A. Antolloni-L. Brumini-F. Fontana-L. Stabile

[8] Galluccio, F. 2018. "L'Accademia delle Scienze di Torino. Sistemi flessibili per l'esposizione e la divulgazione scientifica." MSc. dissertation, Politecnico di Torino. 